\title{
Predictive Value of the Mehran Score for Contrast-Induced Nephropathy after Transcatheter Aortic Valve Implantation in Patients with Aortic Stenosis
}

\author{
Mustafa Zungur ${ }^{a} \quad$ Ilker Gul $^{\mathrm{a}} \quad$ Ahmet Tastan $^{\mathrm{a}}$ Ertan Damar $^{\mathrm{b}}$ Talat Tavli ${ }^{\mathrm{a}}$ \\ Departments of ${ }^{\mathrm{a}}$ Cardiology and ${ }^{\mathrm{b}}$ Anesthesiology and Reanimation, Sifa University Faculty \\ of Medicine, Izmir, Turkey
}

\section{Key Words}

Contrast-induced nephropathy · Mehran risk score $\cdot$ Transcatheter aortic valve implantation

\begin{abstract}
Background/Aims: The Mehran risk score (MS) was adopted to predict the development of contrast-induced nephropathy (CIN) and includes clinical and procedural variables. In this study, we aimed to evaluate the value of MS in the prediction of CIN development after transcatheter aortic valve implantation (TAVI). Methods: Ninety-three patients (47 females; mean age, $77.2 \pm 7.6$ years) who underwent aortic valve replacement with TAVI for severe aortic stenosis in our center between June 2013 and November 2014 were included in the study. Patients were categorized into four risk groups based on MS: low $(\leq 5)$, moderate (6-10), high (11-15), and very high ( $\geq 16)$. Results: CIN was recorded in 24 patients after TAVI (25.8\%). The amount of contrast medium was significantly higher in the CIN+ group $(p=0.029)$, and total mortality was higher in the CIN+ group than in the CIN- group (20.1 vs. $2.9 \%$, respectively; $p=0.024)$. In univariate analysis, diabetes mellitus, coronary artery disease, ejection fraction, baseline creatinine, baseline glomerular filtration rate, contrast medium volume, and MS were found to be significant risk factors for $\operatorname{CIN}(p<0.05$ for all). The receiver operating characteristic analysis of the significant variables in multivariate regression analysis revealed that the cutoff MS to predict the development of CIN was 13.0 (area under the curve, $0.654 ; 95 \%$ confidence interval, $0.495-0.758$; sensitivity, 62\%; specificity, 68\%). Conclusion: MS is a predictor of CIN development after TAVI. We think that the use of MS in clinical practice may decrease renal complications after TAVI.

(c) 2016 S. Karger AG, Basel
\end{abstract}




\section{CardioRenal Medicine}

\begin{tabular}{l|l}
\hline Cardiorenal Med 2016;6:279-288 \\
\hline DOI: 10.1159/000443936 & $\begin{array}{l}\text { @ 2016 S. Karger AG, Basel } \\
\text { www.karger.com/crm }\end{array}$ \\
\hline
\end{tabular}

Zungur et al.: Predictive Value of the Mehran Score for Contrast-Induced Nephropathy after Transcatheter Aortic Valve Implantation in Patients with Aortic Stenosis

\section{Introduction}

Transcatheter aortic valve implantation (TAVI) has emerged as an alternative to surgery for patients with severe symptomatic aortic valve stenosis, particularly for those who were considered at high risk for surgery or were inoperable. Untreated severe aortic stenosis has a high rate of morbidity and mortality [1,2]. TAVI was reported to have lower morbidity and mortality rates compared with medical therapy alone [3]. In studies comparing TAVI and surgical aortic valve replacement, similar rates of efficiency were determined initially [4]. However, recent studies suggested that TAVI is more reliable in high-risk or inoperable patients [5].

Contrast media are used for the purpose of illustration of the alignment of the aortic leaflets during TAVI. The risk of renal function impairment related to radiologic procedures is low in the general population, but it may be very high in selected patient subsets, especially during cardiac catheterization. Renal function that has been stable before TAVI can be deteriorated after the operation. Acute kidney injury that can occur after invasive interventional operations increases morbidity and mortality, particularly in elderly and high-risk patients [6-8]. Contrast-induced nephropathy (CIN) is one of the underlying causes of acute kidney injury [9]. CIN was defined as an absolute increase in serum creatinine ( $\mathrm{SCr}$ ) of $>0.5 \mathrm{mg} / \mathrm{dl}$ or a relative increase of $>25 \%$ within $48-72 \mathrm{~h}$ after TAVI [10].

The factors that could lead to the development of CIN after interventional cardiovascular operations must be well known in order to take preventive measures before or during the operation. Many individual risk factors for the development of CIN have been reported in the literature. The risk of CIN is significantly higher among patients with aortic stenosis undergoing TAVI. Older age, preexisting renal failure, hemodynamic instability, congestive heart failure, diabetes mellitus, anemia, and the use of a large volume of contrast agent are established risk factors for the development of CIN [11]. The Mehran risk score (MS) was adopted to predict the development of CIN and includes clinical and procedural variables: hypotension, intra-aortic balloon pump, congestive heart failure, chronic kidney disease, diabetes, age $>75$ years, anemia, and volume of contrast medium [11].

Although the risk factors for the development of CIN in patients with TAVI have been established before, the predictive value of MS in the development of CIN has not been investigated in detail yet. Therefore, in this study, we aimed to evaluate the value of MS in the prediction of CIN development after TAVI.

\section{Patients and Methods}

Study Design and Patients

This was a prospective follow-up study of 93 patients who underwent aortic valve replacement with TAVI for severe aortic stenosis at Sifa University Hospital between June 2013 and November 2014. Patients who were found to be suitable for TAVI by the heart team council of our center were included in the study. Patients who were already on dialysis before TAVI, with creatinine values $>2.5 \mathrm{mg} / \mathrm{dl}$, and with permanent pacemakers were excluded. Operative risks for patients were calculated using the Logistic European System for Cardiac Operative Risk Evaluation (Logistic EuroSCORE) and the Society of Thoracic Surgeons Predictive Risk of Mortality (STS) scores. Patients with a Logistic EuroSCORE $>20 \%$ or an STS score $>10 \%$ were considered as high-risk patients [12].

Clinical, demographic, and echocardiographic data, processual variables, and morbidity and mortality rates were recorded for 6 months following TAVI. The 1-, 3- and 6-month controls after the discharge of patients were performed at our center.

The study was approved by the institutional ethics committee, and all the study-related procedures were performed according to the latest version of the Helsinki Declaration. All the patients signed an informed consent form before participation in the study. 


\section{CardioRenal Medicine}

\begin{tabular}{l|l}
\hline Cardiorenal Med 2016:6:279-288 \\
\hline DOI: 10.1159/000443936 & $\begin{array}{l}\text { (c) 2016 S. Karger AG, Basel } \\
\text { www.karger.com/crm }\end{array}$ \\
\hline
\end{tabular}

Zungur et al.: Predictive Value of the Mehran Score for Contrast-Induced Nephropathy after Transcatheter Aortic Valve Implantation in Patients with Aortic Stenosis

\section{Study Procedures}

Severe aortic stenosis was diagnosed using echocardiography. A mean aortic gradient $>40 \mathrm{~mm} \mathrm{Hg}$, an aortic valve area $<1 \mathrm{~cm}^{2}$, and a valve area index (valve area/body surface area) $<0.6 \mathrm{~cm}^{2}$ were considered severe aortic stenosis [12]. An Edwards SAPIEN XT valve (Edwards Lifesciences, Irvine, Calif., USA) balloonexpandable device was used for TAVI. A vascular occlusion device (ProStar XL, Abbott Laboratories, North Chicago, Ill., USA) was used in eligible patients in terms of femoral artery diameter and anatomy. The surgical cutdown method was applied in patients who were unsuitable for using the iliac and femoral artery vascular closure device. Transesophageal echocardiography and multislice computed tomography tests were done to determine the diameter of the aortic bioprosthesis. Patients received clopidogrel $75 \mathrm{mg}$, aspirin $100 \mathrm{mg}$, and intravenous antibiotherapy before the procedure. Iohexol (Omnipaque, GE Healthcare Inc., Princeton, N.J., USA), nonionic, low-osmolar monomeric, was used as the contrast medium. The amount of contrast medium was recorded during the procedure. Procedures such as computed tomography and coronary angiography that require the administration of contrast medium were performed at least $72 \mathrm{~h}$ before TAVI. Daily renal function tests were used to monitor the patients from admission to discharge. In addition, creatinine levels were checked in the second week and in the first, third, and sixth month after the procedure.

Estimated glomerular filtration rate (GFR) was calculated using the formula of Modification of Diet in Renal Disease: GFR (expressed in $\left.\mathrm{ml} / \mathrm{min} / 1.73 \mathrm{~m}^{2}\right)=186 \times \mathrm{SCr}^{1.154} \times$ age $^{0.203}(0.742$ for female gender). Before TAVI, $1 \mathrm{ml} / \mathrm{kg} / \mathrm{h}$ of $0.9 \% \mathrm{NaCl}$ solution was implemented for $24 \mathrm{~h}$ to the patients with a GFR $<50 \mathrm{ml} /$ $\mathrm{min} / 1.73 \mathrm{~m}^{2}$. Then, $48-72 \mathrm{~h}$ after TAVI, a $0.5 \mathrm{mg} / \mathrm{dl}$ or $25 \%$ increase compared to the basal creatinine value was evaluated as CIN [10,12-17].

The Mehran CIN risk score included eight clinical and procedural variables: presence of hypotension, congestive heart failure, chronic kidney disease, diabetes, age $>75$ years, anemia, requirement of intra-aortic balloon pump, and the volume of contrast agent used. Patients were categorized into four risk groups based on MS: low ( $\leq 5)$, moderate (6-10), high (11-15), and very high ( $\geq 16)$. Risk groups were compared for all study variables. Patients who developed CIN (CIN+) and those who did not (CIN-) were compared for clinical, demographic, and echocardiographic data; risk factors; processual variables; and morbidity and mortality rates.

\section{Statistical Analysis}

Statistical analysis was performed using SPSS 17.0 software (SPSS, Chicago, Ill., USA). To test the distribution pattern, the Kolmogorov-Smirnov test was used. Continuous variables were expressed as the mean \pm standard deviation (SD), and the categorical variables were expressed as percentages. Comparisons of continuous variables between the two groups were performed using the independent samples t test, and the analysis of variance (ANOVA) test was used for comparing continuous variables of multiple groups. Univariate and multivariate, stepwise backward conditional regression analyses were used to determine the independent predictors of CIN. MS, diabetes mellitus, ejection fraction, coronary artery disease, creatinine, GFR, volume of contrast agent, and hematocrit level were included in the regression analysis. A receiver operating characteristic (ROC) curve analysis was performed to identify the optimal cutoff point of MS to predict CIN in patients with ST elevation myocardial infarction. The area under the curve (AUC) values were calculated as a measure of test accuracy. A two-sided $p<0.05$ was considered significant within a $95 \%$ confidence interval (CI).

\section{Results}

\section{General Characteristics of Patients}

Ninety-three patients (47 females; mean age, 77.2 \pm 7.6 years) were enrolled into the study. CIN was recorded in 24 patients after TAVI (25.8\%). No significant differences between the patients with and without CIN were determined in terms of demographic, laboratory, and echocardiographic characteristics (table 1).

\section{Procedural Data}

A balloon-expandable Edwards SAPIEN XT valve via transfemoral access was implanted in all patients. The mean radiation time was $7.9 \pm 3.3 \mathrm{~min}$. The mean contrast volume and 
Table 1. Demographic and clinical characteristics of the patients

\begin{tabular}{|c|c|c|c|}
\hline & $\mathrm{CIN}+(\mathrm{n}=24)$ & CIN- $(n=69)$ & $\mathrm{p}$ value \\
\hline \multicolumn{4}{|l|}{ Demographics and vital signs } \\
\hline Age, years & $78.7 \pm 6.1$ & $76.7 \pm 8.1$ & 0.263 \\
\hline Female/male & $14 / 10(58.3)$ & $33 / 36(47.8)$ & 0.258 \\
\hline Body mass index & $29.3 \pm 8.3$ & $26.8 \pm 4.1$ & 0.081 \\
\hline Heart rate, beats/min & $76.2 \pm 15.3$ & $77.5 \pm 11.3$ & 0.542 \\
\hline \multicolumn{4}{|l|}{ Blood pressure, $\mathrm{mm} \mathrm{Hg}$} \\
\hline Systolic & $128.1 \pm 28.6$ & $125.2 \pm 19.2$ & 0.212 \\
\hline Diastolic & $77.7 \pm 11.8$ & $74.9 \pm 10.7$ & 0.346 \\
\hline \multicolumn{4}{|l|}{ Medical history } \\
\hline Previous cardiac operation & $2(10.0)$ & $10(16.7)$ & 0.102 \\
\hline $\begin{array}{l}\text { Previous percutaneous coronary } \\
\text { intervention }\end{array}$ & $2(10.0)$ & $18(30.5)$ & 0.058 \\
\hline Coronary artery disease & $11(45.8)$ & $41(62.1)$ & 0.127 \\
\hline Permanent pacemaker & $2(8.3)$ & 0 & 0.066 \\
\hline Diabetes mellitus & $8(33.3)$ & $22(33.3)$ & 0.604 \\
\hline Arterial hypertension & $14(58.3)$ & $42(63.6)$ & 0.412 \\
\hline Chronic obstructive pulmonary disease & $14(58.3)$ & $45(68.2)$ & 0.266 \\
\hline \multicolumn{4}{|l|}{ Echocardiographic findings } \\
\hline \multicolumn{4}{|l|}{ Aortic gradients, mm Hg } \\
\hline Maximum & $81.0 \pm 16.8$ & $87.7 \pm 14.9$ & 0.092 \\
\hline Mean & $49.5 \pm 12.2$ & $50.3 \pm 10.6$ & 0.784 \\
\hline \multicolumn{4}{|l|}{ Aortic valve area, $\mathrm{cm}^{2}$} \\
\hline Before TAVI & $0.63 \pm 0.08$ & $0.62 \pm 0.09$ & 0.475 \\
\hline After TAVI & $1.81 \pm 0.16$ & $1.78 \pm 0.13$ & 0.212 \\
\hline Ejection fraction before TAVI, \% & $45.1 \pm 10.6$ & $41.1 \pm 10.9$ & 0.152 \\
\hline Aortic stenosis grade $\geq 2$ after TAVI, $\%$ & $1 \pm 5.3$ & $4 \pm 6.6$ & 0.938 \\
\hline \multicolumn{4}{|l|}{ Laboratory findings } \\
\hline Brain natriuretic peptide, $\mathrm{pg} / \mathrm{ml}$ & $8,097.4 \pm 9,852.9$ & $3,556.5 \pm 3,313.7$ & 0.001 \\
\hline Glucose, mg/dl & $119.1 \pm 39.7$ & $111.4 \pm 45.5$ & 0.568 \\
\hline Low-density lipoprotein, $\mathrm{mg} / \mathrm{dl}$ & $102.9 \pm 32.1$ & $107.1 \pm 36.5$ & 0.936 \\
\hline Hematocrit, \% & $35.4 \pm 4.3$ & $34.8 \pm 5.3$ & 0.686 \\
\hline \multicolumn{4}{|l|}{ Creatinine, mg/dl } \\
\hline Before TAVI & $1.19 \pm 0.32$ & $1.19 \pm 0.88$ & 0.978 \\
\hline After TAVI & $1.53 \pm 0.43$ & $1.14 \pm 0.94$ & 0.010 \\
\hline Potassium & $4.5 \pm 0.7$ & $4.3 \pm 0.5$ & 0.274 \\
\hline \multicolumn{4}{|l|}{ Risk scoring } \\
\hline Logistic EuroSCORE, \% & $37.0 \pm 10.9$ & $38.2 \pm 15.5$ & 0.414 \\
\hline STS score, $\%$ & $14.5 \pm 9.7$ & $13.8 \pm 8.1$ & 0.874 \\
\hline MS & $14.1 \pm 4.4$ & $10.9 \pm 5.3$ & 0.012 \\
\hline \multicolumn{4}{|l|}{ Hospitalization and outcome } \\
\hline Contrast volume, $\mathrm{ml}$ & $200.6 \pm 63.8$ & $170.6 \pm 54.5$ & 0.029 \\
\hline Intensive care unit stay, days & $1.8 \pm 1.2$ & $1.3 \pm 0.9$ & 0.050 \\
\hline Total hospital stay, days & $4.9 \pm 1.7$ & $4.0 \pm 1.3$ & 0.042 \\
\hline $\mathrm{GFR}, \mathrm{ml} / \mathrm{min} / 1.73 \mathrm{~m}^{2}$ & $52.1 \pm 17.9$ & $63.4 \pm 21.8$ & 0.015 \\
\hline Minor bleeding & $3(12.5)$ & $16(23.2)$ & 0.208 \\
\hline Major bleeding & $3(12.5)$ & $5(7.2)$ & 0.339 \\
\hline Erythrocyte transfusion & $10(41.7)$ & $28(40.5)$ & 0.309 \\
\hline Major stroke & 0 & 0 & _- \\
\hline Mortality, in hospital & $2(8.3)$ & $1(1.5)$ & 0.325 \\
\hline Mortality, $1-6$ months & $3(12.5)$ & $1(1.5)$ & 0.108 \\
\hline Total mortality & $5(20.1)$ & $2(2.9)$ & 0.024 \\
\hline
\end{tabular}

Data are given as $\mathrm{n}(\%)$ or mean \pm SD. Italicized $\mathrm{p}$ values indicate $\mathrm{p}<0.05$. 
Table 2. Clinical features of patients with respect to CIN risk according to MS

\begin{tabular}{|c|c|c|c|c|c|}
\hline & \multicolumn{4}{|c|}{ CIN risk according to MS } & \multirow{2}{*}{$\begin{array}{l}\mathrm{p} \\
\text { value }\end{array}$} \\
\hline & $\begin{array}{l}\text { Low } \\
(n=19)\end{array}$ & $\begin{array}{l}\text { Moderate } \\
(\mathrm{n}=20)\end{array}$ & $\begin{array}{l}\text { High } \\
(\mathrm{n}=28)\end{array}$ & $\begin{array}{l}\text { Very high } \\
(\mathrm{n}=26)\end{array}$ & \\
\hline \multicolumn{6}{|l|}{ Demographics and vital signs } \\
\hline Age, years & $70.2 \pm 8.3$ & $75.0 \pm 6.1$ & $79.4 \pm 5.1$ & $81.1 \pm 6.7$ & $<0.001$ \\
\hline Female/male & $9 / 10(47.4)$ & $13 / 7(65.0)$ & $14 / 14(50.0)$ & $11 / 15(42.3)$ & 0.478 \\
\hline Body mass index & $26.7 \pm 6.5$ & $26.8 \pm 8.8$ & $27.2 \pm 3.5$ & $29.5 \pm 5.2$ & 0.435 \\
\hline Heart rate, beats/min & $71.9 \pm 19.4$ & $75.2 \pm 9.8$ & $78.1 \pm 13.2$ & $71 \pm 14.1$ & 0.618 \\
\hline \multicolumn{6}{|l|}{ Blood pressure, mm Hg } \\
\hline Systolic & $128.1 \pm 18.3$ & $128.6 \pm 13.9$ & $121.3 \pm 12.1$ & $119.2 \pm 29.9$ & 0.312 \\
\hline Diastolic & $76.2 \pm 15.1$ & $77.2 \pm 18.2$ & $79.1 \pm 16.1$ & $75.2 \pm 13.1$ & 0.182 \\
\hline \multicolumn{6}{|l|}{ Medical history } \\
\hline Previous cardiac operation & $1(7.1)$ & $2(10.5)$ & $7(30.4)$ & $2(8.3)$ & 0.317 \\
\hline \multicolumn{6}{|l|}{ Previous percuteneous coronary } \\
\hline intervention & $4(28.6)$ & $4(21.1)$ & 5 (21.7) & $7(30.4)$ & 0.865 \\
\hline Coronary artery disease & $9(52.9)$ & $6(31.6)$ & $18(64.3)$ & $19(73.1)$ & 0.569 \\
\hline Permanent pacemaker & 0 & 0 & $1(3.7)$ & $1(3.8)$ & 0.681 \\
\hline Diabetes mellitus & $4(23.5)$ & $2(10.5)$ & $9(32.1)$ & $15(57.7)$ & 0.146 \\
\hline Arterial hypertension & $9(52.9)$ & $13(68.4)$ & $18(64.3)$ & $16(61.5)$ & 0.804 \\
\hline \multicolumn{6}{|l|}{ Echocardiographic findings } \\
\hline \multicolumn{6}{|l|}{ Aortic gradients, $\mathrm{mm} \mathrm{Hg}$} \\
\hline Maximum & $81.9 \pm 9.6$ & $87.1 \pm 13.5$ & $88.0 \pm 16.1$ & $86.1 \pm 13.8$ & 0.692 \\
\hline Mean & $46.1 \pm 6.2$ & $51.4 \pm 7.3$ & $52.1 \pm 6.9$ & $49.6 \pm 7.3$ & 0.393 \\
\hline \multicolumn{6}{|l|}{ Aort valve area, $\mathrm{cm}^{2}$} \\
\hline Before TAVI & $0.63 \pm 0.14$ & $0.61 \pm 0.11$ & $0.62 \pm 0.19$ & $0.66 \pm 0.15$ & 0.826 \\
\hline After TAVI & $1.78 \pm 0.12$ & $1.76 \pm 0.14$ & $1.81 \pm 0.13$ & $1.77 \pm 0.09$ & 0.286 \\
\hline Ejection fraction before TAVI, \% & $40.1 \pm 8.0$ & $40.2 \pm 6.8$ & $43.7 \pm 7.2$ & $40.2 \pm 5.9$ & 0.279 \\
\hline Aortic stenosis grade $\geq 2$ after TAVI, $\%$ & $1(6.7)$ & $1(5.6)$ & $1(4.2)$ & $2(8.7)$ & 0.982 \\
\hline \multicolumn{6}{|l|}{ Laboratory findings } \\
\hline Brain natriuretic peptide, $\mathrm{pg} / \mathrm{ml}$ & $3,670.0 \pm 2,556.2$ & $5,732 \pm 3,562.1$ & $5,789 \pm 2,846.1$ & $8,570 \pm 4,120.6$ & 0.016 \\
\hline Glucose, $\mathrm{mg} / \mathrm{dl}$ & $122.1 \pm 18.1$ & $102.8 \pm 15.2$ & $107.5 \pm 9.4$ & $120.8 \pm 14.6$ & 0.564 \\
\hline Low-density lipoprotein, mg/dl & $105.4 \pm 20.1$ & $107.9 \pm 21.3$ & $101.1 \pm 16.3$ & $112.4 \pm 14.2$ & 0.177 \\
\hline Triglyceride, mg/dl & $132.5 \pm 24.1$ & $110.1 \pm 28.2$ & $127.3 \pm 19.2$ & $122.1 \pm 20.2$ & 0.537 \\
\hline Hematocrit, \% & $35.1 \pm 5.2$ & $32.1 \pm 5.1$ & $33.1 \pm 6.2$ & $33.3 \pm 6.1$ & 0.197 \\
\hline \multicolumn{6}{|l|}{ Creatinine, mg/dl } \\
\hline Before TAVI & $1.07 \pm 0.18$ & $0.97 \pm 0.18$ & $1.08 \pm 9.4$ & $1.56 \pm 9.4$ & 0.032 \\
\hline After TAVI & $0.97 \pm 0.27$ & $1.02 \pm 0.21$ & $1.21 \pm 0.33$ & $1.63 \pm 0.25$ & 0.035 \\
\hline \multicolumn{6}{|l|}{ Risk scoring } \\
\hline Logistic EuroSCORE, \% & $33.9 \pm 12.2$ & $34.4 \pm 13.1$ & $38.4 \pm 7.2$ & $40.4 \pm 9.1$ & 0.038 \\
\hline STS score, $\%$ & $12.2 \pm 7.6$ & $16.7 \pm 5.4$ & $19.8 \pm 16.2$ & $20.8 \pm 13.7$ & 0.005 \\
\hline \multicolumn{6}{|l|}{ Hospitalization and outcome } \\
\hline Contrast volume, $\mathrm{ml}$ & $138.9 \pm 41.3$ & $177.3 \pm 30.9$ & $178.4 \pm 49.3$ & $207.9 \pm 45.1$ & 0.001 \\
\hline Contrast nephropathy & 0 & $7(35.0)$ & $7(25.0)$ & $10(38.5)$ & 0.022 \\
\hline Intensive care unit stay, days & $1.3 \pm 1.1$ & $1.2 \pm 0.9$ & $1.7 \pm 0.45$ & $1.8 \pm 0.91$ & 0.123 \\
\hline Total hospital stay, days & $4.1 \pm 1.6$ & $3.9 \pm 1.4$ & $4.3 \pm 1.4$ & $5.1 \pm 1.1$ & 0.034 \\
\hline $\mathrm{GFR}, \mathrm{ml} / \mathrm{min} / 1.73 \mathrm{~m}^{2}$ & $72.3 \pm 13.1$ & $67.9 \pm 19.2$ & $58.6 \pm 17.1$ & $48.4 \pm 18.3$ & $<0.001$ \\
\hline Minor bleeding & $5(26.3)$ & $3(15.0)$ & $7(25.0)$ & $4(15.4)$ & 0.674 \\
\hline Major bleeding & 0 & $2(10.0)$ & $3(10.7)$ & $3(11.5)$ & 0.516 \\
\hline Major stroke & 0 & 0 & 0 & 0 & - \\
\hline Mortality, in hospital & $1(5.3)$ & $1(5.0)$ & 0 & $1(3.9)$ & 0.297 \\
\hline Mortality, 1-6 months & 0 & 0 & $1(3.6)$ & $3(11.5)$ & 0.108 \\
\hline Total mortality & $1(5.3)$ & $1(5.0)$ & $1(3.6)$ & $4(15.4)$ & 0.036 \\
\hline
\end{tabular}

Data are given as $\mathrm{n}(\%)$ or mean \pm SD. Italicized $\mathrm{p}$ values indicate $\mathrm{p}<0.05$. 
Zungur et al.: Predictive Value of the Mehran Score for Contrast-Induced Nephropathy after Transcatheter Aortic Valve Implantation in Patients with Aortic Stenosis

Table 3. Univariate and multivariate analysis of risk factors for CIN

\begin{tabular}{|c|c|c|c|c|}
\hline & \multicolumn{2}{|c|}{ Univariate analysis } & \multicolumn{2}{|c|}{ Multivariate analysis } \\
\hline & OR $(95 \%$ CI $)$ & $\mathrm{p}$ value & OR $(95 \%$ CI $)$ & $\mathrm{p}$ value \\
\hline Age & $1.1(0.8-1.4)$ & 0.263 & - & - \\
\hline Diabetes mellitus & $1.5(0.8-2.6)$ & 0.042 & $0.9(0.4-1.1)$ & 0.334 \\
\hline Hypertension & $1.0(0.7-1.3)$ & 0.667 & & \\
\hline Coronary artery disease & $2.0(1.1-4.2)$ & 0.032 & $1.2(1.0-1.6)$ & 0.055 \\
\hline STS score & $0.7(0.4-1.1)$ & 0.874 & - & - \\
\hline Logistic EuroSCORE & $1.1(0.9-1.5)$ & 0.414 & - & - \\
\hline Ejection fraction & $1.3(0.8-1.9)$ & 0.045 & $1.0(0.6-1.7)$ & 0.142 \\
\hline Creatinine & $3.4(1.1-6.1)$ & $<0.001$ & $1.9(1.2-2.7)$ & 0.003 \\
\hline GFR & $3.8(1.5-7.9)$ & $<0.001$ & $2.3(1.2-4.2)$ & 0.006 \\
\hline Contrast volume & $2.9(0.7-8.3)$ & 0.029 & $1.8(1.1-3.5)$ & 0.048 \\
\hline MS & $3.1(0.5-5.5)$ & 0.012 & $2.0(1.1-3.2)$ & 0.026 \\
\hline Hematocrit & $0.8(0.5-1.1)$ & 0.686 & - & - \\
\hline
\end{tabular}

$\mathrm{OR}=$ Odds ratio. Italicized $\mathrm{p}$ values indicate $\mathrm{p}<0.05$

extubation time were $178.3 \pm 33.2 \mathrm{ml}$ and $205.3 \pm 43.1 \mathrm{~min}$, respectively. The length of stay in the intensive care unit and the length of stay in the hospital were determined as $1.6 \pm 1.0$ and $4.4 \pm 1.7$ days, respectively.

\section{CIN and Risk Factors}

When the risk factors were evaluated, the difference between CIN+ and CIN-groups in terms of coronary artery disease, diabetes mellitus, hypertension, chronic obstructive pulmonary disease, and peripheral arterial disease was not ascertained. The CIN+ group's length of stay in the intensive care unit and the length of stay in the hospital were determined as $1.8 \pm 1.2$ and $4.9 \pm 1.7$ days, respectively.

After TAVI, 2 of the patients (2.2\%) needed permanent pacemaker implantation due to an atrioventricular conduction block. Major bleeding occurred in 8 patients, of whom 3 $(12.5 \%)$ were in the CIN+ group $(\mathrm{p}=0.339)$. The patients in the CIN + and CIN-groups did not show a significant difference in terms of stroke and minor bleeding complications (table 1 ).

The amount of contrast medium was significantly higher in the CIN+ group ( $p=0.029)$. Seven patients died during the study period. Three of these patients died in the first month ( 2 patients in the CIN + group and 1 patient in the CIN- group; $\mathrm{p}=0.325$ ). From the first to the sixth month of follow-up, 4 patients died ( 3 patients in the CIN+ group and 1 patient in the CIN- group; $\mathrm{p}=0.108)$. Total mortality was higher in the CIN+ group than in the CINgroup (20.1 vs. $2.9 \%$, respectively; $p=0.024$; table 1 ).

\section{The Mehran CIN Risk Score}

MS was significantly higher in the CIN + patients than in the CIN-patients $(14.1 \pm 4.4$ and $10.9 \pm 5.3$, respectively; $p=0.012$; table 1 ). Patients were classified into four groups according to MS defined as low, moderate, high, and very high. Baseline patient characteristics in each risk group are summarized in table 2. Gender distribution, heart rate, and the presence of coronary artery disease were similar between the groups. The risk of CIN increased proportionately with the age of the patients. Both systolic and diastolic blood pressure at admission, major bleeding, minor bleeding, major stroke, intensive care unit stay, and left ventricular ejection fraction were similar between the MS groups. Comorbidities like hypertension and diabetes were also similar. Patients in the higher-risk group had a higher STS score, Logistic 
Zungur et al.: Predictive Value of the Mehran Score for Contrast-Induced Nephropathy after Transcatheter Aortic Valve Implantation in Patients with Aortic Stenosis

Table 4. ROC analysis for the prediction of CIN by risk factors that were significant in multivariate analysis

\begin{tabular}{lrllll}
\hline & Cutoff & AUC & $\begin{array}{l}\text { Sensitivity, } \\
\%\end{array}$ & $\begin{array}{l}\text { Specificity, } \\
\%\end{array}$ & $95 \%$ CI \\
\hline Contrast volume, $\mathrm{ml}$ & 177.5 & 0.639 & 54 & 65 & $0.510-0.768$ \\
MS & 13.0 & 0.654 & 62 & 68 & $0.495-0.758$ \\
Baseline GFR, $\mathrm{ml} / \mathrm{min} / 1.73 \mathrm{~m}^{2}$ & 54.0 & 0.625 & 67 & 66 & $0.477-0.773$ \\
Baseline creatinine, $\mathrm{mg} / \mathrm{dl}$ & 1.26 & 0.815 & 66 & 76 & $0.717-0.913$
\end{tabular}

Fig. 1. ROC curve for the prediction of CIN using MS. The AUC for the prediction of CIN of MS was 0.654 (sensitivity, $62 \%$; specificity, 68\%; 95\% CI, 0.495-0.758, and cutoff, 13.0).

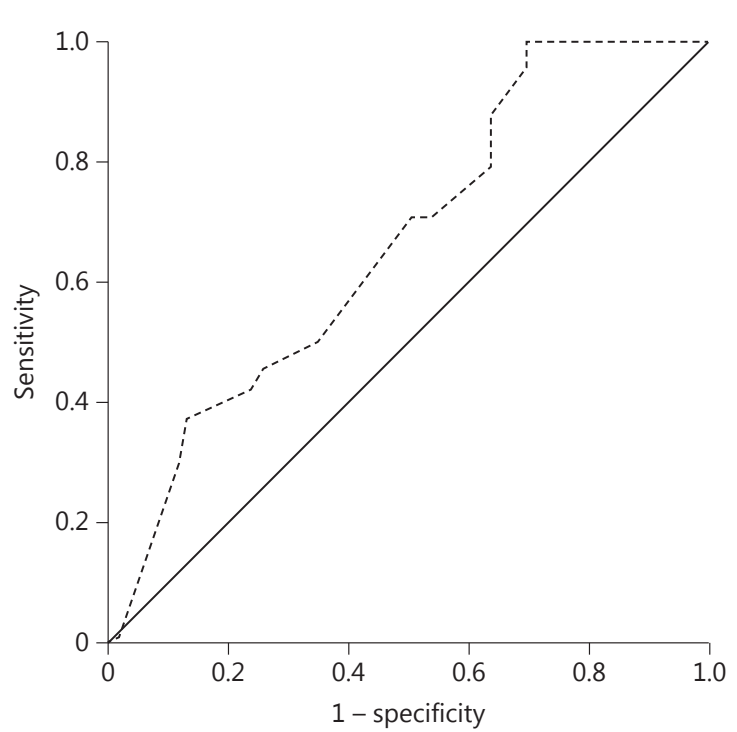

EuroSCORE, and pre- and postprocedural creatinine levels. Total mortality, brain natriuteric peptide, GFR, contrast volume, and CIN were higher in the higher-risk groups (table 2).

\section{CIN Predictors}

In univariate analysis, diabetes mellitus, coronary artery disease, ejection fraction, baseline creatinine, baseline GFR, volume of contrast agent, and MS were found to be significant risk factors for CIN ( $p<0.05$ for all). Thus, the multivariate regression analysis was performed with these variables, where baseline creatinine, baseline GFR, volume of contrast agent, and MS were found to be significant predictors of CIN (table 3).

The ROC analysis of the significant variables in multivariate regression analysis revealed that the cutoff MS to predict the development of CIN was 13.0 (AUC, 0.654; 95\% CI, 0.4950.758 ; sensitivity, $62 \%$; specificity, $68 \%$ ), and the cutoff GFR was $54.0 \mathrm{ml} / \mathrm{min} / 1.73 \mathrm{~m}^{2}$ (AUC, 0.625; 95\% CI, 0.477-0.773; sensitivity, 67\%; specificity, 66\%) (fig. 1; table 4).

\section{Discussion}

In this prospective study, we primarily indicated that MS can be used to predict the development of CIN in patients undergoing TAVI, with a cutoff value of 13.0 and $>60 \%$ sensitivity and specificity. 
After invasive cardiovascular procedures, the mechanism of the kidney damage caused by contrast medium is not exactly clarified. It has been thought that toxicity resulting from the characteristics of the contrast medium and the resultant degree of renal ischemia had a role in the development of CIN. On the other hand, there are also many factors that can make CIN development easier. These can be divided into two groups depending on patient characteristics and invasive surgery. The prominent facilitating characteristics of patients are age, diabetes mellitus, cardiac insufficiency, and impaired basic renal functions [11,18]. However, these variables were not different between the patients with and without CIN in our study (tables 1, 2). Regarding TAVI, factors that facilitate CIN development show an increase in the amount of contrast medium, hemodynamic irregularities, and hypotension [11-17, 19-21]. Particularly, hypotensive episodes during TAVI may increase CIN probability.

According to Nash et al. [9], CIN is one of the most significant causes of hospital-acquired renal insufficiency. CIN prevalence after TAVI has been reported as 10-30\% [22-24]. In our study, CIN was detected in 24 patients $(25.8 \%)$, which was similar to the ratios reported in the literature. A significant increase in morbidity has been reported in earlier studies when cardiovascular pathology coexists with renal dysfunction. Similarly, the development of renal insufficiencies after aortic valve implantations increases mortality [9, 25]. However, in our study, in the first 6 months of follow-up, there was no statistically significant increase in morbidity.

When complications were evaluated separately, the CIN+ group had a higher complication rate than the CIN- group, but this difference was statistically nonsignificant, which may be due to the low number of patients.

Bagur et al. [25] reported that mortality was $7 \%$ in aortic valve implantation without kidney injury, whereas with kidney injury, the rate was 15\%. In our study, mortality rates during the 6-month follow-up were remarkably higher for those who developed CIN (20.1 vs. $2.9 \% ; p=0.024$ ). Even the deterioration in basal kidney function, which can be modified by contrast volume, might lead to CIN development that cannot be totally cured.

MS was developed to predict CIN after percutaneous coronary intervention [11]. It is a valuable predictor of future adverse clinical outcomes in patients with acute myocardial infarction undergoing invasive cardiovascular operations [11]. Although persistent renal dysfunction requiring routine hemodialysis is quite rare after CIN, permanent renal impairment may be observed in up to $45.9 \%$ of patients with CIN [11]. We found that hospital mortality was higher in patients with CIN and positively correlated with MS. In other words, MS was independently associated with CIN. Patients with MS $\geq 13.0$ (sensitivity, $62 \%$; specificity, 68\%) were shown to be at high risk for developing CIN. Both CIN and higher MS are associated with increased mortality and morbidity. Therefore, the intraprocedural measures that can prevent this complication may be beneficial in patients at high risk as identified by MS.

The main limitation of the study was the low number of patients, which precludes us from reaching a definitive conclusion on the predictive value of MS for the development of CIN following TAVI procedure. Additionally, the underlying reasons of CIN development such as radiotoxicity, nephrotoxicity, and ischemia were not put forth in depth because renal biopsy could not be performed. Furthermore, follow-up duration was considerably short; we think that as the duration of follow-up rises, statistical differences would become clear. Nevertheless, this was the first study evaluating the predictive value of MS for the development of CIN following TAVI. The findings of our study should be confirmed by further prospective, large-scale studies; thus, MS can be used in clinical practice for TAVI.

In conclusion, MS is a predictor of CIN development after TAVI even in cases of low morbidity and mortality, and we think that the use of MS in clinical practice may decrease renal complications of TAVI. 


\section{CardioRenal Medicine}

\begin{tabular}{l|l}
\hline Cardiorenal Med 2016;6:279-288 \\
\hline DOI: 10.1159/000443936 & $\begin{array}{l}\text { (C) 2016 S. Karger AG, Basel } \\
\text { www.karger.com/crm }\end{array}$ \\
\hline Zungur et al.: Predictive Value of the Mehran Score for Contrast-Induced Nephropathy
\end{tabular}

Zungur et al.: Predictive Value of the Mehran Score for Contrast-Induced Neph
after Transcatheter Aortic Valve Implantation in Patients with Aortic Stenosis

\section{Acknowledgements}

The authors would like to thank Enago (www.enago.com) for the English language review.

\section{Statement of Ethics}

The study was approved by the institutional ethics committee, and all the study-related procedures were performed according to the latest version of the Helsinki Declaration. All the patients signed an informed consent form before participation in the study.

\section{Disclosure Statement}

The authors declare no conflicts of interest.

\section{References}

1 Turina J, Hess O, Sepulcri F, Krayenbuehl HP: Spontaneous course of aortic valve disease. Eur Heart J 1987;8: 471-483.

2 Cribier A: Development of transcatheter aortic valve implantation (TAVI): a 20-year odyssey. Arch Cardiovasc Dis 2012;105:146-152.

3 Figulla L, Neumann A, Figulla HR, Kahlert P, Erbel R, Neumann T: Transcatheter aortic valve implantation: evidence on safety and efficacy compared with medical therapy. A systematic review of current literature. Clin Res Cardiol 2011;100:265-276.

4 Leon MB, Smith CR, Mack M, Miller DC, Moses JW, Svensson LG, Tuzcu EM, Webb JG, Fontana GP, Makkar RR, Brown DL, Block PC, Guyton RA, Pichard AD, Bavaria JE, Herrmann HC, Douglas PS, Petersen JL, Akin IJ, Anderson WN, Wang D, Pocock S; PARTNER Trial Investigators: Transcatheter aortic-valve implantation for aortic stenosis in patients who cannot undergo surgery. N Engl J Med 2010;363:1597-1607.

5 Adams DH, Popma JJ, Reardon MJ, Yakubov SJ, Coselli JS, Deeb GM, Gleason TG, Buchbinder M, Hermiller J Jr, Kleiman NS, Chetcuti S, Heiser J, Merhi W, Zorn G, Tadros P, Robinson N, Petrossian G, Hughes GC, Harrison JK, Conte J, Maini B, Mumtaz M, Chenoweth S, Oh JK; US CoreValve Clinical Investigators: Transcatheter aorticvalve replacement with a self-expanding prosthesis. N Engl J Med 2014;370:1790-1798.

6 Rihal CS, Textor SC, Grill DE, Berger PB, Ting HH, Best PJ, Singh M, Bell MR, Barsness GW, Mathew V, Garratt KN, Holmes DR Jr: Incidence and prognostic importance of acute renal failure after percutaneous coronary intervention. Circulation 2002;105:2259-2264.

7 Aregger F, Wenaweser P, Hellige GJ, Kadner A, Carrel T, Windecker S, Frey FJ: Risk of acute kidney injury in patients with severe aortic valve stenosis undergoing transcatheter valve replacement. Nephrol Dial Transplant 2009;24:2175-2179.

8 Nuis RJ, Van Mieghem NM, Tzikas A, Piazza N, Otten AM, Cheng J, van Domburg RT, Betjes M, Serruys PW, de Jaegere PP: Frequency, determinants and prognostic effects of acute kidney injury and red blood cell transfusion in patients undergoing transcatheter aortic valve implantation. Catheter Cardiovasc Interv 2011;77: 881-889.

9 Nash K, Hafeez A, Hou S: Hospital-acquired renal insufficiency. Am J Kidney Dis 2002;39:930-936.

10 Mehran R, Nikolsky E: Contrast-induced nephropathy: definition, epidemiology, and patients at risk. Kidney Int Suppl 2006;100:11-15.

11 Dangas G, Iakovou I, Nikolsky E, Aymong ED, Mintz GS, Kipshidze NN, Lansky AJ, Moussa I, Stone GW, Moses JW, Leon MB, Mehran R: Contrast-induced nephropathy after percutaneous coronary interventions in relation to chronic kidney disease and hemodynamic variables. Am J Cardiol 2005;95:13-19.

12 Yamamoto M, Meguro K, Mouillet G, Bergoend E, Monin JL, Lim P, Dubois-Rande JL, Teiger E: Comparison of effectiveness and safety of transcatheter aortic valve implantation in patients aged $\geq 90$ years versus $<90$ years. Am J Cardiol 2012;110:1156-1163.

13 Hayashida K, Lefèvre T, Chevalier B, Hovasse T, Romano M, Garot P, Mylotte D, Uribe J, Farge A, Donzeau-Gouge P, Bouvier E, Cormier B, Morice MC: True percutaneous approach for transfemoral aortic valve implantation using the Prostar XL device: impact of learning curve on vascular complications. JACC Cardiovasc Interv 2012; 5:207-214.

14 Hayashida K, Bouvier E, Lefèvre T, Hovasse T, Morice MC, Chevalier B, Romano M, Garot P, Mylotte D, Farge A, Donzeau-Gouge P, Cormier B: Impact of CT-guided valve sizing on post-procedural aortic regurgitation in transcatheter aortic valve implantation. EuroIntervention 2012;8:546-555. 
15 Levey AS, Bosch JP, Lewis JB, Greene T, Rogers N, Roth D: A more accurate method to estimate glomerular filtration rate from serum creatinine: a new prediction equation. Modification of Diet in Renal Disease Study Group. Ann Intern Med 1999;130:461-470.

16 Mueller C, Buerkle G, Buettner HJ, Petersen J, Perruchoud AP, Eriksson U, Marsch S, Roskamm H: Prevention of contrast media-associated nephropathy: randomized comparison of 2 hydration regimens in 1,620 patients undergoing coronary angioplasty. Arch Intern Med 2002;162:329-336.

17 Goldenberg I, Matetzky S: Nephropathy induced by contrast media: pathogenesis, risk factors and preventive strategies. Can Med Assoc J 2005;172:1461-1471.

18 Chertow GM, Levy EM, Hammermeister KE, Grover F, Daley J: Independent association between acute renal failure and mortality following cardiac surgery. Am J Med 1998;104:343-348.

19 Wi J, Ko YG, Shin DH, Kim JS, Kim BK, Choi D, Ha JW, Hong MK, Jang Y: Prediction of contrast-induced nephropathy with persistent renal dysfunction and adverse long-term outcomes in patients with acute myocardial infarction using the Mehran risk score. Clin Cardiol 2013;36:46-53.

20 Mehran R, Aymong ED, Nikolsky E, Lasic Z, Iakovou I, Fahy M, Mintz GS, Lansky AJ, Moses JW, Stone GW, Leon MB, Dangas G: A simple risk score for prediction of contrast-induced nephropathy after percutaneous coronary intervention: development and initial validation. J Am Coll Cardiol 2004;44:1393-1399.

21 Vahanian A, Alfieri O, Andreotti F, Antunes MJ, Barón-Esquivias G, Baumgartner H, Borger MA, Carrel TP, De Bonis M, Evangelista A, Falk V, Lung B, Lancellotti P, Pierard L, Price S, Schäfers HJ, Schuler G, Stepinska J, Swedberg K, Takkenberg J, Von Oppell UO, Windecker S, Zamorano JL, Zembala M; ESC Committee for Practice Guidelines (CPG); Joint Task Force on the Management of Valvular Heart Disease of the European Society of Cardiology (ESC); European Association for Cardio-Thoracic Surgery (EACTS): Guidelines on the management of valvular heart disease (version 2012): the Joint Task Force on the Management of Valvular Heart Disease of the European Society of Cardiology (ESC) and the European Association for Cardio-Thoracic Surgery (EACTS). Eur J Cardiothorac Surg 2012;42:1-44.

22 Karkouti K, Wijeysundera DN, Yau TM, Callum JL, Cheng DC, Crowther M, Dupuis JY, Fremes SE, Kent B, Laflamme C, Lamy A, Legare JF, Mazer CD, McCluskey SA, Rubens FD, Sawchuk C, Beattie WS: Acute kidney injury after cardiac surgery: focus on modifiable risk factors. Circulation 2009;119:495-502.

23 Lok CE, Austin PC, Wang H, Tu JV: Impact of renal insufficiency on short- and long-term outcomes after cardiac surgery. Am Heart J 2004;148:430-438.

24 Elhmidi Y, Bleiziffer S, Piazza N, Hutter A, Opitz A, Hettich I, Kornek M, Ruge H, Brockmann G, Mazzitelli D, Lange R: Incidence and predictors of acute kidney injury in patients undergoing transcatheter aortic valve implantation. Am Heart J 2011;161:735-739.

25 Bagur R, Webb JG, Nietlispach F, Dumont E, De Larochellière R, Doyle D, Masson JB, Gutiérrez MJ, Clavel MA, Bertrand OF, Pibarot P, Rodés-Cabau J: Acute kidney injury following transcatheter aortic valve implantation: predictive factors, prognostic value, and comparison with surgical aortic valve replacement. Eur Heart J 2010; 31:865-874. 